\title{
Usina Hidrelétrica no Tocantins e sujeitos na construção da consciência jurídica: o reassentamento Córrego Prata em Porto Nacional (TO)
}

\section{Hydroelectric dam in Tocantins and a subjects in the construction of legal consciousness in resettlement Corrego Prata in Porto Nacional (TO)}

Fabian Serejo Santana - Mestre em Ciências do Ambiente, Universidade Federal do Tocantins, Palmas (TO). E-mail: fabianserejo@gmail.com

Temis Gomes Parente - Doutora em História, Professora do Curso de Mestrado em Desenvolvimento Regional e Professora de História da Universidade federal do Tocantins, Palmas (TO). E-mail: temis@uft.edu.br

\begin{abstract}
Resumo
A construção de grandes barragens foi a estratégia adotada no Brasil face à crescente demanda decorrente da expansão industrial e do crescimento populacional dos grandes centros urbanos. O passivo desse desenvolvimento, além dos impactos ambientais, tem sido o deslocamento e realocação de grandes populações, dando origem a diversos tipos de reassentamentos. Os reassentados de Córrego Prata, Tocantins, são pessoas que tiveram sua história de vida bruscamente transformada pelo impacto causado com a construção da barragem. Muitas dessas pessoas não sabiam o que fazer, pois o deslocamento desestrutura o padrão de organização social da população envolvida, desarticula suas redes comunitárias, de parentesco e amizades, comprometendo a identidade coletiva e territorial dessas famílias atingidas. Sem saber quais são seus direitos, os reassentados contam com as intervenções e intermediações de sujeitos como o Movimento dos Atingidos por Barragens, o Ministério Público Estadual e a Associação, composta pelos atingidos. Em face disso, neste artigo discute-se como se forma a consciência jurídica dessas comunidades, no bojo do processo de remanejamento e reassentamento, e como estes sujeitos interferem e contribuem neste processo de conhecer e exigir os seus direitos.
\end{abstract}

\section{Palavras-chave}

Direito. Direitos Humanos. Consciência Jurídica. Sustentabilidade. Reassentamento.

\begin{abstract}
The construction of large dams was the strategy adopted in Brazil face the increasing demand from industrial expansion and population growth of large urban centers. The liability of this development, in addition to environmental impacts, is the displacement and relocation of large populations, giving rise to various types of resettlement. Resettlers are people who have had their life story abruptly transformed by the impact with the construction of the dam. Many of these people did not know what to do, because the displacement disrupts the pattern of social organization of the population involved, dismantles their community networks of kinship and friendship, compromising the collective and territorial identity of the affected families. Without knowing what your rights are resettlers have the assistance and intermediation of subjects such as the Movement of People Affected by Dams, and State Prosecutor 's Association, composed of the hit. On the face of it, this article, we discuss how to shape the legal awareness of these communities, in the midst of relocation and resettlement process, and how these subjects affect and contribute this to know and demand their rights process.
\end{abstract}

\section{Keywords}

Law. Human Rights. Legal Awareness. Sustainability. Resettlement. 


\section{INTRODUÇÃO}

A Usina Hidrelétrica Luís Eduardo Magalhães, localizada entre os municípios de Miracema e Lajeado, notabilizou-se por ser o primeiro grande empreendimento no estado do Tocantins (TO). Com o barramento, formou-se um reservatório ${ }^{1}$ que inundou uma área total de $630 \mathrm{~km}^{2}$ e $170 \mathrm{~km}$ de extensão, afetando os municípios de Miracema do Tocantins, Lajeado, Palmas, Porto Nacional, Brejinho de Nazaré e Ipueiras e, em decorrência do alagamento, foram afetadas 997 famílias, totalizando 4.407 pessoas (THEMAG, 1998). Os reassentamentos surgiram como uma das medidas mitigadoras, em decorrência da construção da usina. Do montante de famílias atingidas, 363 foram remanejadas para 12 projetos. São eles: Boa Sorte, Canto da Serra, Projeto 2000, Mundo Novo, Brejo Alegre, Córrego Prata, Flor da Serra, Luzimangues, Mariana, Olericultores, Pinheirópolis Rural, São Francisco de Assis (SILVA JÚNIOR, 2007).

No reassentamento do Prata, localizado a $44 \mathrm{~km}$ do município de Porto Nacional, a 22 km de Palmas, capital do Tocantins, às margens da rodovia TO-050, foram reassentadas ${ }^{2} 91$ famílias, e outras 82 foram permutadas, número que foi gradativamente diminuindo, face ao processo de adaptação das famílias atingidas. Segundo dados do Plano de Desenvolvimento do Projeto de Reassentamento (PDR, 2002), a maioria dos reassentados não eram proprietários de terras, mas lavradores, olericultores, caseiros, vaqueiros e formadores de chácaras, que também conquistaram o direito à terra e à produção da autossubsistência.

O remanejamento compulsório a que foram submetidos estes atingidos provocou efeitos na realidade social, muito além da capacidade reparatória da desapropriação, posto que em muitos casos não foram respeitados os direitos individuais e coletivos, fazendo-se valer de uma relação de flagrante desigualdade.

Tal deslocamento desestruturou o padrão de organização social da população envolvida, desarticulando suas redes comunitárias, de parentesco e amizades, comprometendo assim a identidade coletiva e territorial dessas famílias atingidas. Dentre as propostas de compensação pelas perdas materiais, sociais e culturais foram edificados reassentamentos, entre os quais está o Córrego Prata. Entretanto, as famílias remanejadas não tiveram direito à escolha do local onde

\footnotetext{
Dados oficiais disponíveis no site da INVESTICO (2011). Disponível em: http://www. investco.com.br/ dados usina/reservatorio/reservatorio.asp. Acesso em: 3 nov. 2013.

2 Nos Relatórios de Impacto Ambiental, as principais formas de reparação para a população atingida por barragens têm sido: a) Indenização amigável: ocorrendo quando há compra e venda direta; b) Desapropriação: quando ocorre processo judicial que decide pela desapropriação de propriedade e benfeitorias; c) Permuta: quando ocorre a troca de terra por terra; d) Remanejamento: quando ocorre a transferência da população atingida para reassentamentos construídos pela empresa responsável pela construção da barragem.
}

Novos Cadernos NAEA •v. 16 n. 2 • p. 121-148 • dez. 2013 
foi edificado o reassentamento e passaram por um processo de ressignificação desse novo lugar, a partir do estabelecimento de novos relacionamentos e papéis sociais.

A voz dessas populações atingidas, porém, tem se erguido face ao contínuo desrespeito aos seus direitos. Embora sejam em grande parte amparadas por Órgãos do Poder Público, Associações, Organizações Não Governamentais (ONGs), a exemplo do Movimento dos Atingidos por Barragens (MAB) e do Ministério Público (MP), os quais assumem o papel de defensores ou mediadores da causa dos atingidos, seria possível afirmar que essas populações estavam conscientes de seus direitos e politicamente organizadas para exigi-los ou seriam apenas peças de um jogo de poder à mercê de forças e interesses do capital privado e das políticas dos governos?

Diante disso, emerge o seguinte problema: Como se formou a consciência jurídica desta comunidade, no bojo do processo de remanejamento e reassentamento, para enfim se tornar politicamente organizada e empreender ações capazes de exigir e confirmar seus direitos?

Na perspectiva de Melo (1998), é na consciência jurídico-social que se formam as representações jurídicas referentes às normas que devam existir e como as mesmas devam ser. A consciência jurídica tem relação com o senso comum valorativo do indivíduo ou da sociedade, no que se refere à capacidade de decidir sobre o justo ou o injusto, o que seja socialmente útil ou inútil, com incidência sobre as normas de conduta.

Para a consecução desta pesquisa, utilizou-se a metodologia do estudo de caso, por ser considerado representativo de muitos outros estudos semelhantes. O estudo de caso é a estratégia preferida quando se colocam questões do tipo "como" e "por quê", quando o pesquisador tem pouco controle sobre os eventos e quando "o foco se encontra em fenômenos contemporâneos inseridos em algum contexto da vida real" (YIN, 2001, p. 19), fundamentando-se nos princípios teóricos de metodologia qualitativa, que consiste em descrições detalhadas de situações, eventos, pessoas, interações e comportamentos que são observáveis.

$\mathrm{Na}$ medida em que o trabalho avançou, o objetivo central de analisar o processo de formação da consciência jurídica nos impactados pela UHE Luís Eduardo Magalhães no reassentamento Córrego Prata foi sendo atingido através das especificidades, tais como: 1) realização do levantamento documental da comunidade impactada, como memórias de reuniões, artigos de jornais, atas, estatutos, ofícios, Termos de Ajustes de Condutas (TACs) e outros documentos, investigando-se de que forma a consciência jurídica foi sendo sistematizada e registrada; 2) analisaram-se os registros documentais produzidos nas audiências 
públicas, reuniões das associações e ações judiciais promovidas pelos atores envolvidos, no intuito de verificar o envolvimento e interesse da população na busca por seus direitos; 3) pesquisou-se como os assentados se tornaram politicamente organizados e quais as ações que empreenderam para ampliar e garantir os seus direitos; 4) descreveu-se o trabalho desenvolvido pelos agentes mediadores e reguladores entre os reassentados e a empresa empreendedora; 5) avaliaram-se quais os direitos que não foram respeitados, quais foram conquistados em decorrência dos processos de negociação, os que não foram implementados e como a população reassentada se mobilizou para exigi-los.

Para tanto, levou-se em consideração as experiências pessoais, compartilhadas em entrevistas com 46 famílias remanescentes, haja vista a maioria ter abandonado o reassentamento, vendendo suas propriedades por não terem se adaptado e suportado as dificuldades desse novo lugar. Ao final, conclui-se que esses reassentados desenvolveram uma nova mentalidade, no que diz respeito a conhecer e lutar pelos seus direitos.

\section{AÍ EU PEGUEI E FALEI: RAPAZ VOU FICAR SEM NADA?}

Aí chegou lá pra avisar: Você vai ser retirado daqui porque vai ser formado um lago (José de Ribamar Rocha da Silva) ${ }^{3}$.

Quando a notícia chega, já está tudo decidido. O ribeirinho, tomado de surpresa, não sabe o que fazer. Olha para a terra: as crianças brincando no quintal, a mulher estendendo as roupas, as galinhas ciscando... Em pouco tempo, passa tudo em sua mente. As experiências e sonhos construídos naquele lugar vão ser levados com as águas do lago. $\mathrm{Na}$ experiência do senhor Antônio Vieira, reassentado pela INVESTCO ${ }^{4}$, essa água nunca chegaria a sua casa, porém, mesmo sem querer acreditar, tem que fazer sua escolha: uma casa no mato ou na cidade? Pensa: "Fazer o quê na cidade?” Para depois decidir...

Quando chegou um personagem da INVESTCO lá. Primeiro saiu um cara lá fazendo umas picadas. Ah, essa água vai chegar até aqui e tal [...] Eis

\footnotetext{
Entrevista concedida a Fabian Serejo Santana, 15/12/2011. Todos os entrevistados citados neste artigo autorizaram a transcrição e divulgação de seus depoimentos, assinando um Termo de Consentimento Livre e Esclarecido, constando o nome completo, em ordem alfabética, data em que foi realizada a entrevista, endereço do entrevistado e o tempo que reside no reassentamento.

4 A INVESTCO S.A. foi criada em novembro de 1997, composta pelas empresas participantes do Consórcio Lajeado, que venceu o processo de licitação e assinou o contrato de concessão em dezembro de 1997, para construir e operar o empreendimento na região do Lajeado até 2032. Disponível em:<http://www.investco.com.br/empresa/historico/historico.asp $>$. Acesso em: 3 nov. 2013.
}

Novos Cadernos NAEA • v. 16 n. $2 \cdot$ p. 121-148 • dez. 2013 
que de repente poderia vim um distúrbio de água e vim até aqui. Ali não poderia fazer nada naquela área [...] Aí ele me perguntou se eu queria uma casa na cidade ou uma casa no mato. Uma chácara fora da cidade, uma casa com água e luz, um hectare de terra pronto pra plantar [...]. Aí então eu calculei... Pensei comigo mesmo [...] Eu sou analfabeto, já sou velho então o que eu vou fazer na cidade. Ah eu quero é uma casa no mato (Antônio Vieira da Silva. Entrevista concedida Fabian Serejo Santana ${ }^{5}$, 2011).

De um modo geral, esta foi a primeira reação dos atingidos pela barragem, e posteriormente reassentados. O desespero foi ainda maior na experiência de Iderval Barbosa, que estava em tratamento de saúde na cidade. Quando retornava à fazenda onde trabalhava como caseiro, não encontrou mais nada no lugar:

Rapaz eu tava na cidade [...] beira do rio, sabe? Mas nem na época entendi, aí, aí depois é que fui descobrir [...] levaram tudo, aí fiquei carente. Aí eu peguei e falei: Rapaz vou ficar sem nada? (Iderval Barbosa da Silva. Entrevista concedida a FSS, 2011).

Essa mesma reação de espanto e descrença é percebida por Karpinski (2007, p. 74) no estudo dos atingidos pela UHE de Salto Caxias: "Não acreditar numa obra destas significava a própria condição de vida, pois, como viver com a certeza de que um dia tudo que estavam construindo poderia ser tragado pelas águas?" Passado o impacto inicial, na maioria dos casos, os atingidos assumem uma atitude de resignação, à espera do que vai acontecer. Desarticulados e sem o conhecimento dos seus direitos, muitos acabam sendo enganados e deixam de receber uma reparação justa pelos danos que lhes foram causados. A situação dos atingidos por barragens não é muito diferente da maioria das pessoas que não tiveram acesso à educação e têm os seus direitos desrespeitados.

São situações como estas que fazem surgir os seguintes questionamentos: Como, e em que momento tais pessoas adquirem a consciência de seus direitos? Onde nasce a consciência jurídica? Seria um atributo natural do homem, que se manifesta com o seu desenvolvimento ou depende de algum tipo de estrutura específica para manifestar-se? Faria parte de qualquer tipo de sociedade ou apenas daquelas ditas desenvolvidas? Como pequenos agricultores, a maioria não alfabetizados, começam a se organizar e reivindicar direitos? Como se dá esse processo de despertamento que rompe com uma postura resignada e se contrapõe aos detentores do poder de mando?

O termo consciência não pode ser tomado de forma isolada ou aplicado em qualquer contexto, por isso, parte-se do pressuposto de que existe uma plurissignificação desse termo, sendo, portanto, pertinente discutir em qual

Doravante será usada a abreviatura FSS para o entrevistador. 
sentido será tomado, ou seja, sobre que aspecto da consciência o termo será abordado. Partindo-se da teoria de $V_{y g o t s k y}{ }^{6}$, entende-se que a consciência é um produto social, e que é na sociedade civil, segundo o conceito de Bobbio (2007), que se desenvolve a gênese do Direito. Neste sentido, compreende-se que o reassentado toma consciência de que é ator no palco das relações jurídicas que se desencadeiam na sociedade.

Partindo de uma análise do pensamento hegeliano, Salgado (2006) compreende que a consciência jurídica está localizada no interior da razão prática, tendo como pressuposto a dialética entre consciência teórica, pela qual se realiza como razão. A razão prática inclui a consciência moral e jurídica, enquanto esta nasce como resultado da consciência ética:

A consciência jurídica pressupõe o nós da consciência teórica e começa a sua operação de valorar a coisa ou o objeto depois de a consciência teórica cumprir a faina do conhecer-se como razão. Desse modo, é um processo que culmina na consciência ética total ou razão jurídica, que traz em si o momento imediato da consciência moral no plano da subjetividade, mas que já passou pela razão teórica, uma vez que como consciência jurídica é consciência de um nós, por força da universalidade que lhe é própria (SALGADO, 2006, p.22-23).

A partir dos estudos de Ferreira (2002) sobre a consciência moral, compreende-se que ação consciente é aquela voltada para um fim e, nesta perspectiva, procura-se entender como o reassentado resolve deixar de aceitar passivamente tudo que lhe é imposto e começa a reivindicar seus direitos. Estas abordagens são fundamentais para formação da consciência jurídica. Neste sentido, procura-se entender de que forma o reassentado compreende o que é direito e como se aplica à sua realidade de vida.

Neste sentido, aplicando-se à realidade vivenciada pelo atingido por barragem, verifica-se que a primeira reflexão é tentar entender o que está acontecendo ao seu redor, quando percebe que o fenômeno da barragem é inevitável e que o seu mundo será desconstruído, procura compreender o mundo externo, sente-se impotente e busca respostas. O reassentado desconhece o lugar para onde está sendo levado e também não pode evitá-lo.

Quando chega ao reassentamento e se vê diante do desconhecido, o reassentado toma consciência de que o seu mundo precisa ser reconstruído. Descobre que não está só, que existem outros vivendo os mesmos dilemas, sem respostas, reféns da obscuridade, da ignorância e desinformação:

${ }_{6}$ A teoria de Vygotsky foi extraída a partir das abordagens de Toassa (2006) e Neves (2005).

Novos Cadernos NAEA • v. 16 n. $2 \cdot$ p. 121-148 • dez. 2013 
Então esse reassentado, que é de conhecimento pouco, meio cismado, às vezes pode ser uma coisa de benefício pra ele e pode pensar que é uma coisa ruim né, então uns ficaram meio cismados. A gente não sabia o que ia acontecer, aguardando o convite deles pra vim receber a terra, a casa e a terra, ninguém sabia. Nós, não teve movimento nenhum, ninguém sabia de nada, não teve reunião, não teve aviso, nem nada (José Martins da Silva. Entrevista concedida a FSS, 2011).

Essa incerteza e a falta de conhecimento presente no relato de José Martins revela a falta de consciência coletiva, sentido derivado da palavra consciência, do latim "conscientia", isto é, ter conhecimento de alguma coisa comum a muitas pessoas, senso íntimo, "ter conhecimento de". Ferreira (2002) chama a atenção para a formação do termo, onde: scientia + cum significa "saber com" destacando a figura do conscius, aquele que sabe com o outro ou com outros, ou seja, o confidente, o cúmplice, a testemunha. A autora destaca um primeiro sentido de consciência, como "reflexão que o sujeito capaz de razão faz no sentido de se desdobrar e recuar para se observar e se julgar. É a nós que a nossa consciência toma como testemunhas" (Ibid., p. 45).

Essa ideia de alteridade pode ser extraída da evolução do conceito de consciência em Vygostsky (TOASSA, 2006). Inicialmente, a consciência é uma relação de alteridade; posteriormente, é um processo e produto passíveis de análises semióticas concretas e também em termos de interações sistêmicas cerebrais. A consciência é sempre consciência mediada de alguma coisa: é a própria relação da criança com o meio e, de modo mais tardio, da pessoa consigo própria.

Foi assim na experiência dos reassentados do Prata, o outro se tornou o referencial, pois a maioria não se conhecia. Deu-se início a uma fase de conhecer o outro para entender a sua própria realidade. Cada um passou a relatar de onde veio, o que fazia e como chegou até o reassentamento. Era uma forma de buscar algum tipo de afinidade nesse novo projeto a ser construído. Descobriram com a presença do outro que não se tratava de um projeto individual. Eles precisavam um do outro, precisam se organizar, se conhecer e construir uma consciência coletiva.

É neste momento que alguns sujeitos vão sendo identificados como atores fundamentais no processo de construção dessa consciência, que a priori seria apenas a consciência de que fazem parte de uma população atingida pela barragem e que fazem parte de um lugar chamado Reassentamento Córrego Prata. Desse momento em diante já não serão chamados de caseiros, vaqueiros ou agricultores, mas reassentados, uma palavra nova que os qualifica, e que traz significados que precisam ser compreendidos. 
$\mathrm{Na}$ concepção de Foucault, não existe um sujeito pronto, acabado, cuja identidade seja cristalizada. Os sujeitos estão sempre se constituindo nas diversas relações de poder inscritas na sociedade, havendo múltiplas e distintas maneiras de ocorrer um processo de subjetivação no decorrer da história, em que os sujeitos podem manter, fixar ou transformar suas identidades (KARPINSKI, 2007, p. 82). O conceito de poder para Foucault (FURLIN, 2011, p. 4) não é algo situado ou fixado nas estruturas estatais ou jurídicas, mas funcionando nas malhas das relações humanas e, por isso, disseminado nas estruturas sociais, que produzem indivíduos, sujeitos e sujeitados.

Daí a importância desses sujeitos que integram a realidade do reassentamento, que Zitzke (2007, p. 4) identifica como atores compondo uma complexa rede, segundo a qual "a UHE do Lajeado desenvolveu-se a partir desse conjunto heterogêneo de peças que foram se encaixando, de entidades e materiais que foram sendo mobilizados e deslocados, de atores que foram assumindo determinados papéis".

A partir das pesquisas realizadas com a população atingida e análise da formação do reassentamento, destacamos pelo menos três sujeitos que consideramos de fundamental importância no processo de formação da consciência jurídica dessa comunidade. O primeiro é o Movimento dos Atingidos por Barragens (MAB), que se apresenta como uma organização que deseja esclarecer os direitos que os reassentados possuem e promover a mobilização das comunidades para exigir esses direitos. O segundo sujeito nesse processo é o Ministério Público Estadual ${ }^{7}$ (MPE), que se interpõe no processo como mediador dos conflitos entre a Associação dos reassentados e a empresa responsável pelo empreendimento, a INVESTCO. O terceiro é a Associação formada pelos reassentados, que se torna personalizada nos discursos do reassentamento, como entidade que os representa, mas que nem sempre agrada a todos.

O papel de cada um desses sujeitos contribuiu para a formação da consciência jurídica, na medida em que se conectam em certo momento, pois o advento do reassentamento proporcionou essa conexão e tornou possível a tomada de consciência de um determinado grupo de pessoas que foi impactado pela construção de uma barragem, e que se viu diante de uma nova realidade, que exigiu de seus protagonistas habilidades para construir uma nova identidade a partir dessa consciência ou como parte dela.

No restante do artigo será usada apenas a expressão Ministério Público ou MP como referência ao Ministério Público Estadual.

Novos Cadernos NAEA • v. 16 n. $2 \cdot$ p. 121-148 • dez. 2013 


\section{AÍ DEPOIS APARECEU AQUI UMA PESSOA CHAMADA MAB}

Aí depois apareceu aqui uma pessoa chamada MAB, né. MAB você sabe como é? MAB são aqueles que trabalham pelos reassentados. Que foram impactados. Então eles começaram a acompanhar esse MAB. Mas você sabe como são as coisas hoje, cada qual devia o seu. Cada qual destroce o seu (Antônio Vieira da Silva. Entrevista concedida a FSS, 2011).

O primeiro sujeito a ser analisado no processo de formação da consciência jurídica atua como um agente que visa esclarecer, informar e mobilizar os reassentados para exigir os direitos da comunidade, o Movimento dos Atingidos por Barragem (MAB) ou apenas "Movimento", como muitos chamam na própria comunidade. Sua importância nesse processo revela que é na sociedade e nos conflitos sociais que se manifesta a gênese do direito, e onde cada cidadão se descobre como sujeito titular de direitos.

O MAB surgiu em 1970, no contexto de novas aspirações dos movimentos sociais, marcado, sobretudo, por uma crise energética mundial causada pelo petróleo, consolidando-se com a necessidade de novas fontes para a geração de energia no Brasil. Nessa década, o país vivia em plena ditadura militar, um período marcado pela supressão dos direitos civis e políticos, mas também pela resistência e luta pela redemocratização e garantia de direitos.

Segundo Foschiera (2009), as origens do MAB estão ligadas a ações pontuais da Igreja Católica e/ou Luterana ${ }^{8}$ e à oposição sindical, vinculandose, posteriormente, à Central Única dos Trabalhadores (CUT) e ao Partido dos Trabalhadores (PT), fatos que contribuíram para a formação de um movimento de âmbito nacional. As principais bandeiras do Movimento eram a luta por indenizações justas e mudança das políticas do setor elétrico ${ }^{9}$, que tinham objetivos desenvolvimentistas, propondo formas alternativas de obtenção de energia (eólica, pequenas centrais elétricas-PCHs, de biomassa etc.).

Segundo Cirineu da Rocha ${ }^{10}$, representante do MAB do Tocantins, o movimento atua em cada região onde se inicia o processo de construção de uma barragem. As atividades de conscientização das comunidades que serão atingidas têm início antes mesmo do começo das obras. Cada organização local é chamada de núcleo ou de base, e tem uma coordenação local composta pelas pessoas que serão atingidas pela barragem. Se vários municípios forem atingidos, como foi

8 Neste sentido, é importante a leitura de Paiva (1985), que trata da relação da Igreja Católica com as questões agrárias e do enfrentamento dos conflitos sociais no campo.

9 Reis (1998) reconstitui a trajetória de lutas do MAB, a partir da região do Alto Uruguai (SC/RS).

10 As informações sobre o MAB no Tocantins foram extraídas do depoimento de Cirineu da Rocha, geógrafo, representante estadual do Movimento. Entrevista concedida a FSS, 2009 e 2011. 
o caso da UHE Lajeado, cada um terá sua própria coordenação, que tomará as decisões pertinentes àquela comunidade.

É importante destacar que entre os instrumentos de conscientização encontra-se a educação ${ }^{11}$. Segundo Corrêa (2007), o MAB vem construindo em nível nacional, articulado ao Movimento Por Uma Educação do Campo, uma proposta pedagógica denominada "Pedagogia dos Povos Atingidos", realizando práticas educativas de alfabetização de pessoas jovens, adultas e idosas atingidas, cujo objetivo é o fortalecimento e ampliação da luta do Movimento por políticas públicas para a educação e o desenvolvimento do campo, buscando formas modernas para despertar a consciência política dos atingidos.

Sobre o processo de conscientização realizado com os atingidos pela UHE Luís Eduardo Magalhães, Cirineu da Rocha analisa as dificuldades estruturais para reunir as pessoas, dada a extensão do lago e a variedade de comunidades atingidas:

Porque no caso da barragem de Lajeado o lago, ele foi alagando de uma forma muito extensa. Deu trabalho. Atingiu muitas pessoas, muita comunidade diferente. $\mathrm{O}$ trabalho é juntar todas as comunidades para ver se elas conseguem construir propostas juntas. Construir, esta tem sido a estratégia que nos temos utilizado. Agora tem muita barragem que tem sido construída, ou que está em processo de construção que a gente não consegue fazer o trabalho... temos dificuldade de levar pessoas pra lá, chegar lá, não temos condições de levar pessoas até lá. Estrutural mesmo, recursos, condições (Cirineu da Rocha. Entrevista concedida a FSS, 2011).

De acordo com Vainer e Araújo (1990), existem três estratégias básicas relativas à desapropriação e deslocamento das populações ocupantes das áreas destinadas à implantação das hidrelétricas: a desinformação, a perspectiva territorial patrimonialista e a negociação individual. Analisada sob essa perspectiva, a estratégia do Movimento procura inviabilizar a primeira delas, a desinformação.

A desinformação está diretamente ligada à propaganda ideológica que procura inserir a ideia do desenvolvimento ${ }^{12}$ da região, na população atingida.

11 Um exemplo dessas técnicas é o projeto audiovisual de educação popular "Cinema Circulante", que foi estudada por Santana (2008) como instrumento na elevação da consciência política e social de quatro militantes do Movimento dos Atingidos por Barragens da região de Chapada dos Guimarães. Segundo o autor, as oficinas do projeto disponibilizaram aos seus alunos os conhecimentos e as ferramentas para transpor o status de sujeito puramente receptor de produtos audiovisuais, para um status de ator/realizador de produtos audiovisuais, potenciando sua capacidade de atuação política através de um procedimento de alfabetização audiovisual.

12 Segundo Carvalho (2006, p. 147) é nesse momento do conflito que cada ator expõe seus argumentos, a fim de justificar a sua posição. O Estado justifica a construção de hidrelétricas pela necessidade de ampliar o fornecimento de energia, para o benefício da nação, possibilitando a geração de empregos, considerando a construção de uma hidrelétrica um evento importante para o desenvolvimento nacional.

Novos Cadernos NAEA •v. 16 n. 2 • p. 121-148 • dez. 2013 
Esse discurso ideológico é retratado nos estudos de Müller (1995), França e Souza (2012) e Parente (2008). De acordo com Mccully (1996, p. 2 apud VIANA, 2003), mais do que simples máquinas geradoras de eletricidade e armazenamento de água, as barragens representam, em concreto, rocha e terra, a ideologia dominante da era tecnológica. Como ícones do desenvolvimento econômico e do progresso científico, as barragens representam o triunfo da dominação do homem sobre a natureza. No caso específico do Tocantins, Parente (2008) afirma que o discurso desenvolvimentista nasce com o projeto de emancipação do Estado, antigo norte de Goiás, aparecendo como caminho do desenvolvimento de uma região que se encontrava em grande atraso. Foi com esse discurso de superação de atraso que se iniciou a construção da Usina Luís Eduardo Magalhães.

Para a liderança do MAB não é possível barrar uma hidrelétrica, principalmente quando esta já teve o seu projeto com todas as licenças legais aprovadas, pois, neste caso, existe o interesse do Estado que se impõe. É o que admite Cirineu:

$\mathrm{Na}$ atual conjuntura política é muito difícil hoje barrar uma obra. E quando ela vai realmente ser efetivada, ela passou por toda a tramitação legal, autorização e tudo, então o restante agora é negociar o que tem para negociar (Cirineu da Rocha, entrevista citada, 2011).

Convém lembrarque nas relações jurídicas envolvendo os empreendimentos de barragens e população atingida, a primeira impressão é de que o grande interesse é da empresa ou consórcio que constrói a barragem, entretanto, a quem interessa diretamente o empreendimento senão ao próprio Estado, como ente administrativo. Assim, o atingido toma consciência de que o seu direito de propriedade está submisso ao interesse maior da sociedade, que é tutelada pelo Estado, restando-lhe apenas pleitear uma justa reparação.

Nestas circunstâncias, a visão do MAB é a de garantir fundamentalmente a negociação pela criação dos reassentamentos, pois, a partir dessa conquista, podem avançar nas questões estruturais como educação, saúde e produção. É preciso garantir a todos os atingidos as condições para viver e se desenvolver. $\mathrm{O}$ MAB acredita que os reassentamentos são uma conquista e uma forma mais justa para repor aquilo que as pessoas perderam com o advento da hidrelétrica.

No início, o reassentado vê com desconfiança a presença do MAB no reassentamento, mas esse medo vai sendo eliminado à medida que participam das reuniões e compreendem o objetivo do Movimento:

Era meio desconfiado... pois quando nós conhecemos aqui, eles não eram muito aceito. Mas depois eu peguei a acompanhar a reunião deles, eu vi que eles trabalhavam a favor do impactados. Porque se nós soubesse que 
nós tinha algum direito antes de nós vim pra cá, a gente tinha entrado de outra forma (Antônio Vieira da Silva. Entrevista citada, 2011).

É a partir das reuniões que os militantes se apresentam à comunidade e tentam esclarecer quais são os direitos do reassentado e como se mobilizar para exigi-los. Nas primeiras reuniões, os reassentados comparecem cheios de dúvidas e medo, mas aos poucos vai se definindo o perfil de cada um, em termos de grau de envolvimento com o Movimento que está nascendo no reassentamento.

Muitas vezes o Movimento é personificado por seus militantes ou lideranças, haja vista o reassentado algumas vezes se referir ao líder como se fosse o próprio Movimento. Neste ponto, percebe-se que o alvo do Movimento é gerar uma identidade naqueles que se envolvem com mais profundidade, promovendo uma assimilação e identificação com a visão do MAB.

No processo de formação da consciência, o movimento social tem um objetivo maior, qual seja, a transformação do indivíduo-ator em sujeito do processo. A reflexão contemporânea sobre o sujeito é desenvolvida também pelo sociólogo e historiador AlainTouraine ${ }^{13}$, para quem o sujeito ou a construção do indivíduo como ator só existe como movimento social, como contestação da lógica da ordem.

Nas entrevistas, distingue-se essa transformação de ator para sujeito no discurso de alguns reassentados, muitos deles marcados por frases cujo vocabulário encontra-se marcado por palavras ou expressões que representam aspectos ideológicos do movimento. A consciência é formada a partir da inserção do reassentado, quando este se encontra em uma realidade maior do que a conhecida. Nas palavras de Maria Antônia, a seguir, a experiência de ter viajado até Brasília com integrantes do $\mathrm{MAB}$, despertou uma consciência dos direitos que, em suas palavras, se houvesse acontecido anteriormente ao impacto da hidrelétrica, a história seria escrita de outra forma:

Eu tive em Brasília. Aí a gente reconheceu o direito dos outros que são atingidos por barragem, se na época que a gente foi atingido por barragem aqui, Tocantins, se a gente tivesse ido a Brasília, tivesse entrado com aqueles parlamentares em Brasília, tivesse reconhecido os direitos da gente, eu acho que hoje em dia a gente estaria numa coisa melhor (Maria Antônia da Silva. Entrevista concedida a FSS, 2011).

Analisando os depoimentos, verifica-se que esse processo de tomada de consciência mediada pela ação do MAB, enquanto sujeito do processo, não se configura de forma impositiva, isto é, sem a anuência do reassentado. Sobretudo

13 Os conceitos de sujeito de Alain Touraine podem ser encontrados em suas obras: Poderemos viver juntos? (1998), Crítica da modernidade (2002) e A busca de si (2004).

Novos Cadernos NAEA • v. 16 n. 2 • p. 121-148 • dez. 2013 
porque nem todos simpatizavam com a metodologia do Movimento, isto, porém, não significa que os não simpatizantes não tenham se tornado sujeitos. Para Cirineu da Rocha, seja qual for a posição de cada um, o importante era que o reassentado compreendesse a "importância da luta":

Neste sentido, para o MAB, o mais importante não é se o reassentado vai se tornar um militante, mas que este se posicione enquanto sujeito que toma consciência dos seus direitos, buscando-os individualmente ou juntando-se a outros sujeitos do reassentamento.

\section{MINISTÉRIO PÚBLICO É QUEM SEMPRE DEFENDE, QUEM ESTÁ DO LADO DOS MAIS FRACOS}

O MP foi elevado pela Carta Magna à condição de defensor da sociedade tanto na esfera penal, como detentor exclusivo da ação penal pública, quanto na esfera cível, tendo como premissa fiscalizar os demais poderes públicos para que sejam observados os princípios da legalidade e moralidade administrativa, sendo, inclusive, o titular do inquérito civil público e da ação civil pública.

Enquanto sujeito, são duas as formas de atuação do Ministério Público no processo de formação da consciência jurídica: primeiro, quando interfere nas negociações entre empresa e reassentados como fiscal da lei; e, segundo, buscando garantir um processo justo e igualdade das partes nesta relação de desiguais.

Como entidade instituída constitucionalmente para defender a sociedade, o MP se qualifica como sujeito capaz de interferir no processo de instalação de grandes hidrelétricas, pois estão em pauta interesses da sociedade, como as questões ambientais e o deslocamento de populações.

A pesquisa realizada com os reassentados permitiu-nos compreender a visão que eles tinham do Ministério Público, enquanto sujeito que se inseriu no processo de negociação entre o reassentamento e a empresa. Sem pré-definir questões fechadas, os reassentados foram questionados sobre o papel ou a importância do Ministério Público para os reassentados.

O reassentado Bolívar Mendanha classificou muitas reuniões como de "alta periculosidade" e, neste caso, a participação do MP significou para ele a garantia de segurança no processo de negociação. Em outro aspecto da pesquisa, o reassentado atribui ao MP a conquista do direito de aumento da propriedade, ressalvando que o órgão deveria ter agido com dureza em todo o processo, para garantir mais direitos aos reassentados. O clima hostil presente nas reuniões de 
negociação também é citado por Iderval Barbosa, que avalia como excessivo o fato dos reassentados recorrerem ao MP para apaziguar ou solucionar os conflitos:

Teve várias brigas ai,mas sempre o pessoal vai pro Ministério Publico. Toda confusão que tem, eles vão pro Ministério Publico. É resolvido lá. Eu nunca precisei do Ministério Publico graças a Deus [...]. Também (foi importante) porque teve muita gente ai que, qualquer confusão era Ministério Publico. (Iderval Barbosa da Silva. Entrevista concedida a FSS, 2011).

A exemplo do MAB, também se verificou que não existia unanimidade sobre o papel ou importância do MP para os reassentados. Havia aqueles que viam pouca ajuda por parte do MP e aqueles que destacam o seu papel como fundamental para conscientizar os reassentados e garantir seus direitos. Para o reassentado João Batista, por exemplo, a contribuição do MP não foi tão significativa para o reassentamento:

Esse aí eu não vou lhe responder não porque ajudou muito pouco. No meu ponto de vista eu não vou atingir todo mundo. Dizem que a corda só quebra do lado mais fraco prá quem tem menos valor, é o caso de nós aqui. A gente foi muito maltratado e $90 \%$ do que eles prometeram para nós, aqui não saiu (João Batista Evangelista. Entrevista concedida a FSS, 2011).

Entretanto, para o reassentado Sebastião Pereira, o MP foi importante para conscientizá-lo a procurar os seus direitos:

Aí eu aprendi a procurar os direitos, porque muitas a gente aprendeu, coisas boas no Ministério Público, porque lá tem gente inteirada, gente com muita sabedoria, sincero, mas só que essas pessoas não têm o poder de definir do começo ao final, você sabe disso né, o promotor mesmo, Promotor Estadual, aí já tem o Procurador do Estado, já mais acima, aí já tem o Tribunal de Justiça, já acima dele, ele tem vontade de decidir, mas talvez não pode. Mas são pessoas sérias... ajudou a esclarecer muitas coisa boas (Sebastião Pereira Cruz. Entrevista concedida a FSS, 2011).

Outro depoimento a ser destacado foi do representante do MAB, Cirineu da Rocha, para quem o MP exerceu um importante papel como garantidor do processo de negociação, o espaço de debate e os direitos dos reassentados:

Principalmente em Lajeado o papel do Ministério Público foi muito importante para garantir o processo de negociação, para garantir o direito. Claro que é assim, eu tenho essa visão, o próprio do Ministério Público tinha falado que não fez mais que a obrigação constitucional dele. Nesta região aqui eu acho que tanto o Ministério Público Estadual quanto

Novos Cadernos NAEA • v. 16 n. 2 • p. 121-148 • dez. 2013 
Federal cumpriram com o papel. Não é que ele foi lá e abraçou a causa do atingido, não, ele garantiu o espaço de debate e diálogo entre a empresa e os reassentados (Cirineu da Rocha. Entrevista citada, 2011).

No depoimento acima, nota-se que a principal função do MP foi garantir um processo justo no qual a população afetada tivesse acesso à justiça. Neste caso, o MP não interferia diretamente na negociação e nos acordos firmados entre a empresa e o impactado. Sua função era garantir o direito da coletividade, por isso atuava diretamente nas reuniões da associação dos reassentados e na mediação dos acordos coletivos, que eram firmados através de um documento jurídico chamado Termo de Ajuste de Conduta (TAC).

A principal função do MP não é garantir a felicidade individual do reassentado, mesmo porque essa seria uma tarefa impossível, haja vista a heterogeneidade do conceito de satisfação. Poderia parecer mais simples indicar um índice de satisfação dos reassentados no processo de negociação ou na análise sobre o papel do Ministério Público, através de uma pesquisa quantitativa. Entretanto, tal aferição seria apenas uma máscara da realidade medida por números. Mais importante é perceber a reflexão que o reassentado faz ao final do processo de negociação e instalação do reassentamento, quando julgam se o processo foi justo ou injusto, igual ou desigual, vantajoso ou prejudicial à comunidade. Essas investigações indicam a formação do processo de conscientização, em que cada reassentado tem agora a capacidade de argumentar e se posicionar sobre o processo ao qual foi submetido.

\section{JUNTAVA TODOS DO REASSENTAMENTO... CADA UM FALAVA A NECESSIDADE DO COMPANHEIRO, CADA UM BRIGAVA PELA MESMAS COISAS}

O terceiro sujeito no processo de formação da consciência jurídica é a Associação Reassentamento Prata ${ }^{14}$. É nela que se travará o principal debate e surgirão conflitos inevitáveis. É nesta arena ${ }^{15}$ que se revelarão relações de poder, que não se travam apenas entre a estrutura estatal e a comunidade atingida - ou entre esta e a empresa que construiu a barragem. As relações de poder

14 A Associação Reassentamento do Prata encontra-se registrada no Livro de Registro das Pessoas Jurídicas, livro $\mathrm{n}^{\circ} \mathrm{A}-12$, às folhas 1.298, datado de 02/07/2002, no Cartório de Pessoas Jurídicas e Documentos e Tabelionato de Protesto de Notas - Pathion Pereira Lima, na comarca de Porto Nacional (TO).

15 Zitzke (2007, p. 227) chama de "arena do reassentamento" ou "arena agrícola" aquela onde atuam as famílias reassentadas, os técnicos extensionistas do governo estadual, o MAB e os técnicos do empreendedor, incluindo-se, neste caso, a Associação como lócus dos debates. 
se encontram entrelaçadas em todas as relações possíveis e vivenciadas no reassentamento: no interesse pela representação política dos reassentados, nos discursos da militância do Movimento, na construção dos templos religiosos, na escola, no posto de saúde e até no domínio de um galpão comunitário.

Essa perspectiva das relações de poder foi discutida por Bobbio (2007), sob a ótica da esfera política, na expressão da estrutura totalizante do Estado e sua superioridade exercida sobre a sociedade civil. Porém, Foucault ${ }^{16}$ estendeu essa reflexão para além das dicotomias Estado-Sociedade Civil. Os poderes não se localizam em um determinado ponto da estrutura social, ao contrário, caracterizam-se como uma rede de dispositivos ou mecanismos, isto é, a tecnologia do corpo, do olhar, da disciplina, dessa forma, não se pode escapar.

Se comparado com Bobbio, não há dicotomias, pois o poder não é algo que se possa deter ou possuir como uma coisa ou uma propriedade. Não existem, portanto, "detentores do poder" de um lado e "dever de obediência" do outro lado, pois, a rigor, para Foucault, o poder não existe - o que existe são práticas ou relações de poder.

Quando se trata do direito do atingido, não se pode interpretá-lo restritivamente pelo direito individual, pois a barragem não interfere apenas na vida de um indivíduo isoladamente. O processo desencadeado por uma barragem modifica toda uma estrutura social e, portanto, essa visão mais ampla abrange os setores econômico, social, cultural e ambiental dessa comunidade afetada.

Na Figura 1 apresentamos um mapa mostrando uma visão geral sobre a área de inundação do lago formado pela UHE Luís Eduardo Magalhães e a localização dos reassentamentos. Em extensão, o reassentamento do Prata é o maior, porém, deve-se ressaltar que também estão incluídas as áreas de terras pertencentes ao projeto de irrigação e fruticultura São João, sobre o qual trataremos mais diante.

Inicialmente, o reassentamento foi composto ${ }^{17}$ por pequenos produtores rurais, antigos moradores de fazendas localizadas no entorno de Palmas e Porto Nacional e de outros povoados localizados às margens do rio Tocantins: Gleba II e III, Canela, Córrego Comprido, Córrego Matança, Carreira Comprida, Jaú e Jaú II, Vila da Balsa, setor aeroporto, Pinheirópolis (PDR, 2002).

\footnotetext{
Essa síntese da ideia de poder encontra-se na obra Microfísica do Poder (FOUCAULT, 1997).

17 Dados extraídos a partir do Plano de Desenvolvimento do Reassentamento Córrego Prata, realizado em 2002.
}

Novos Cadernos NAEA • v. 16 n. 2 • p. 121-148 • dez. 2013 
Figura 1. Mapa com localização dos reassentamentos da UHE Luís Eduardo Magalhães.

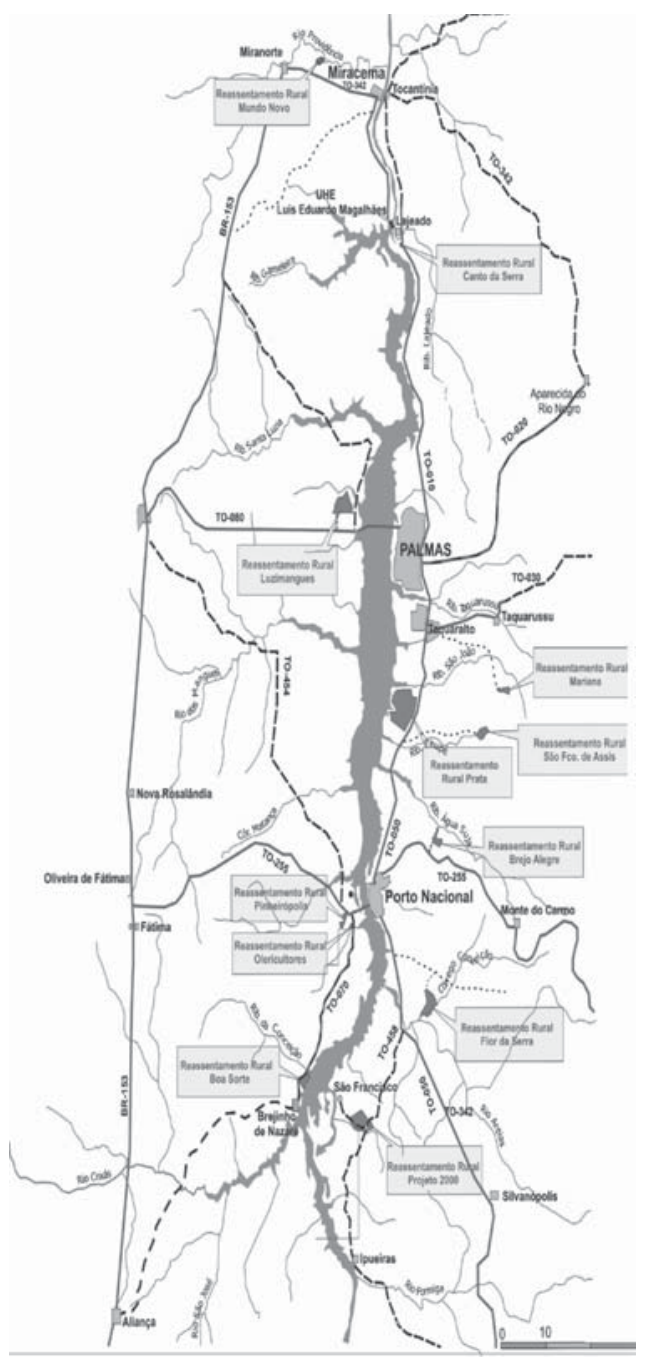

Fonte: Silva Júnior (2007), adaptado de Investco (2003).

A realidade do reassentamento Córrego Prata é um quadro de contradições, pois, em uma mesma área é possível ver propriedades prósperas, com plantio irrigado e proprietários chegando e saindo em suas caminhonetes; e, do outro, ver lotes que parecem estar abandonados, onde, em lugar de frutas, cresce o capim. Muitos impactados perderam suas fontes de renda e se sentiram perdidos, pois possuíam a terra, mas não tinham recursos para investir.

A Associação do Reassentamento Prata foi criada em 18/05/2002, quando a comunidade se reuniu no Colégio Municipal Ercina Monteiro Pereira, 
localizada no Reassentamento do Prata, contando, nesse dia, com 20 membros fundadores ${ }^{18}$. Nesta ocasião elegeram a primeira diretoria da Associação. Logo depois, outros reassentados foram se associando. Em 2/10/2002, foram acrescidos 45 novos associados.

Para o MAB, a constituição de uma associação seria a criação de um espaço adequado para gerar o discurso de luta pelos direitos dos atingidos. Nessa concepção, o MAB buscava lideranças que se alinhassem com a visão do movimento e, dessa forma, pudessem implantar a sua forma de pensar e conduzir o processo de realocação dos atingidos. Nessa perspectiva, a ação do MAB visava produzir uma identidade coletiva do Movimento através da Associação dos reassentados.

A ideia principal era fazer com que a população se sentisse responsável pelas reivindicações e se engajasse na conquista de seus direitos. Assim, na perspectiva do MAB, a Associação não se fundamentava apenas nas lideranças do movimento, mas, principalmente, no engajamento da comunidade dos atingidos:

Sim! era bem participativo o povo sempre em todo lugar tem uns mais acomodado, mas tem uns muito envolvido ai sempre tinha. Juntava todos do reassentamento, cada um tem uma certa quantidade de gente, cada um falava a necessidade, a necessidade do companheiro, cada um brigava pela mesma coisa... (Dionísia Pereira Lima. Entrevista citada, 2011).

As pesquisas demonstraram que a visão dos reassentados sobre o papel da Associação se enquadrava em pelo menos quatro grupos. O primeiro grupo era composto por aqueles que viam na Associação uma forma da comunidade lutar pela melhoria do direito de todos e como meio de um maior engajamento de cada reassentado. A principal característica desse grupo é o alinhamento com visão de movimentos sociais, principalmente influenciada pelos discursos da militância do MAB. Para as pessoas que se enquadravam nesse grupo, a Associação devia levar o reassentado para a mobilização, que poderia se expressar de várias formas: nas marchas ${ }^{19}$, no acampamento em instalações da empresa, nas visitas

18 Conforme Ata de Criação da Associação Reassentamento do Prata (18.05.2002), os membros fundadores da Associação foram: José Martins da Silva, José Raimundo Rodrigues da Silva, Sonia Maria Ferreira de Santana, João Bezerra dos Santos, Emiliano Araújo Dias Neto, Floraci Vasconcelos dos Santos, Lourença Pereira Lima, Cleuzimar Pereira Araújo, Lindaura Ferreira dos Santos Freitas, Cristiano de Oliveira Filho, Valter Nunes dos Santos, Marlene Carvalho de Oliveira, João Batista Evangelista, Otair Soares de Oliveira, Manoel Faria da Silva, Raimundo Souza dos Santos, Pedro Mendonça dos Santos, Daniel Alves dos Santos, João da Cruz Lopes da Silva, todos trabalhadores rurais residentes do Reassentamento.

19 Além das lutas em cada local, existem lutas nacionais conjuntas, como em 2004, quando as negociações não avançavam com o governo Federal. O MAB decidiu fazer uma marcha, mais de 500 atingidos de vários estados caminharam durante 13 dias, de Goiânia a Brasília, fazendo a denúncia dos projetos de construção de barragens e o tratamento das populações atingidas (MAB, 2005).

Novos Cadernos NAEA • v. 16 n. $2 \cdot$ p. 121-148 • dez. 2013 
a outros reassentamentos ${ }^{20}$ e nas viagens para outros municípios de atingidos por barragens e até viagens mais distantes, como o Distrito Federal. O segundo grupo era composto por aqueles reassentados que assumiam uma atitude mais passiva, e esperavam que a Associação resolvesse os problemas da comunidade, mas, de um modo geral, não se envolviam nas ações ou nos projetos propostos pela entidade.

Havia um terceiro grupo, que seria composto por aqueles que criticavam a Associação, por entenderem que ela servia para beneficiar apenas uma parcela da comunidade, sobretudo aqueles ligados à liderança. Essas críticas revelam o quanto as relações de poder se entrelaçam na estrutura social e fogem de uma visão simplista e dicotômica. Esses posicionamentos nem sempre são assumidos publicamente nos debates, pois alguns preferem se distanciar e se excluem do processo decisório. Há, porém, os que assumem seus posicionamentos sobre as questões tratadas pela Associação. Percebe-se, por exemplo, no episódio do envolvimento da Associação oferecendo doações para construção de um templo religioso, que um dos reassentados, Orlando Carvalho, se opõe, defendendo que o dinheiro deveria ser aplicado em benefício da comunidade. O interessante é que, ao final, foi registrado no livro de ata: "o senhor Orlando criou toda essa problemática”.

Também faziam parte desse grupo aqueles que não se envolviam de forma alguma, ou seja, os que tinham conhecimento da existência da Associação, eram convocados para participar, mas preferiam não se envolver:

Associação! Associação aqui para uns tem, para outros não tem. Se você quiser gradear uma terra você tem que pagar. Agora mesmo já era para ter plantado. Mas ninguém tem dinheiro para mandar gradear, até agora nunca plantou (Joana Martins Alves. Entrevista concedida a FSS, 2011).

O quarto grupo seria composto pelos reassentados que estavam mais voltados para os aspectos produtivos. Neste sentido, a importância da Associação residia no envolvimento da comunidade voltada para produção de riqueza e lucro. O aspecto político e social era menos importante que o econômico, e a Associação era vista mais como uma cooperativa do que como uma entidade que lutasse pelos direitos da coletividade:

20 Segundo Silva Júnior (2007), a implantação do Programa de Remanejamento da População Rural causado pela UHE Lajeado redundou no reassentamento coletivo de 363 famílias nos municípios de Miracema do Tocantins, Lajeado, Porto Nacional, Ipueiras e Brejinho de Nazaré, distribuídos em 12 projetos. São eles: Boa Sorte, Canto da Serra, Projeto 2000, Mundo Novo, Brejo Alegre, Córrego Prata, Flor da Serra, Luzimangues, Mariana, Olericultores, Pinheiropolis Rural e São Francisco de Assis. 
Eu acho que no papel, falando teoricamente, quando fala associação é bonito. É um nome assim bem bonito [...] função social, mas bem na verdade, na prática, não tem funcionado. Não funcionou aqui, nem funciona em lugar nenhum. Pelo seguinte, eu pensava que a ideia de um provedor, por exemplo, nós estamos indo para um reassentamento, o projeto que vai ser firmado lá dentro, uma cooperativa, por quê? Porque cooperativa fala de lucros, de interesses, associado não, associado qualquer um pode falar, são coisa sem fins lucrativos não tem muita, eu acho assim (Bolivar Alves Mendanha. Entrevista concedida a FSS, 2011).

Essa divisão interna revela os atores que compõem a estrutura do reassentamento e a postura por eles assumidas. Vai modelando a identidade da Associação. Todavia, a construção dessa identidade é resultado de um processo histórico que compreende as reuniões, discussões e ações de mobilização da Associação, que pode ser percebida mais nitidamente através de uma revisão dos principais eventos registrados no livro de atas da entidade.

\section{HOJE A GENTE SABE ENXERGAR AS COISAS DE OUTRA FORMA}

$\mathrm{Na}$ abordagem da consciência jurídica ou consciência do Direito, devese levar em consideração duas concepções clássicas: o Direito Natural e o Direito Positivo. Por Direito Natural compreende-se um conjunto de princípios universais e aspirações jurídicas de determinada época, que surgem da natureza social do homem, como afirma Nader (2011, p. 79). O Direito Positivo é a ordem jurídica institucionalizada pelo Estado, portanto, obrigatória em um determinado tempo e lugar. As diversas formas de expressão jurídica admitidas pelo sistema adotado pelo Estado configuram o Direito Positivo (NADER, 2001, p. 80).

Partindo-se dessas duas concepções gerais, e com base nos depoimentos dos reassentados, constatou-se que a concepção de direito transita entre essas duas premissas. O reassentado sabe que tem os seus direitos, mas não sabe precisar quais são. Verificou-se que os reassentados mudaram paulatinamente as suas concepções de vida, de direitos e de mundo. Pode-se classificar essa tomada de consciência em dois tempos: antes de serem realocados e depois de terem passado pelo processo de negociações, que envolveram a participação direta dos sujeitos discutidos nesta pesquisa.

Quando interrogados se, hipoteticamente, a construção da barragem se desse naquele momento da pesquisa, o entrevistado agiria diferente - ou se a sua maneira de pensar havia mudado - e como agiria? As respostas dos reassentados foram no sentido de que teriam ações diferentes. As falas demonstraram 
amadurecimento e mudança de mentalidade, pois a maioria havia vivenciado as experiências. Nos depoimentos a seguir, tem-se uma ideia dessa mudança proporcionada pelo processo de consciência jurídica:

Eu mudaria. As cobranças que a gente teve, por exemplo, seria bem diferente né, uma área de terra maior, tudo num lugar só, transporte, máquina pra esse pessoal trabalhar pelo menos, vamos supor, um trator subsidiado, esse dinheiro que eles gastava pagando numa equipe de máquina pra preparar o solo toda vida, ou seja, tudo pra trabalhar ali depois dos primeiros anos, até que alguém da comunidade pudesse tomar conta daquilo, que seja, um grupo, por exemplo, pudesse tomar conta daquelas máquinas, pra ficar dentro ali, em vez deles ter... (José Martins Silva. Entrevista citada, 2011).

José Martins reflete sobre a ótica de quem foi líder da Associação seguindo uma linha mais concentrada na estrutura que garantisse o modo de vida da comunidade e a sustentabilidade econômica. Averigua-se que a consciência jurídica não é algo isolado; ao contrário, ela se conecta com todas as áreas da vida social, econômica e cultural de um indivíduo ou sociedade. Para Alf Ross (1977, p. 358 apud FERREIRA, 2002, p. 179), a consciência jurídica é uma extensão social da consciência moral, e, enquanto reação diante de norma para cumpri-las ou modificá-las, será fundada, necessariamente, ou numa revelação sobrenatural de princípios eternos de justiça ou em interesses predominantes do meio social.

No depoimento de Evangelina da Costa, a mudança causada pela consciência jurídica se traduz em termos de luta pelo seu direito:

Eu não deixaria eles tomarem conta do que a gente tinha de graça. É claro que eu tinha ido procurar meu direito, igual muitos foram depois que a maioria apanhou, muitos foram o projeto lá do Peixe, vários lutaram, alertando as pessoas. Porque as pessoas já estão conscientes. Já andaram nos outros reassentamentos, nas outras coisas, já viram como eles fizeram com os moradores, aí eles lá estão na deles (Evangelina da Costa Amorim. Entrevista citada, 2011).

A consciência de luta emerge da apropriação do discurso dos movimentos sociais. Não significa que a pessoa necessariamente tenha se tornado um militante do Movimento, mas assimilou a ideia de que o direito é uma conquista e que é necessário lutar para alcançá-lo. É a consciência de que o direito é bilateral, como afirma Salgado (2006, p. 80), “o direito refere-se ao outro, não, porém, a um outro passivo, senão armado de uma faculdade que se torna invencível". Se o direito é o bem almejado, para Ferreira (2002, p. 213), o devido não é a coisa, mas o ius (latim: direito), portanto, o direito subjetivo, o devido ao sujeito de direito, enquanto seu direito. É exatamente por isso que o dever de atribuir a cada um o seu direito não é moral, mas jurídico, pois, exigível. 
No depoimento de Bolivar Alves, a tomada de consciência transcende o direito pessoal, expande-se para uma consciência de amplitude política, social e ambiental.

Ah! Muita! Passou por muitas transformações - a minha mentalidade hoje é totalmente diferente, hoje a gente sabe enxergar as coisas de outra forma, a gente vê, hoje, porque na verdade o enchimento de um lago desses traz muitas mudanças em todos os aspectos, traz aos olhos das pessoas um progresso muito grande para nós, quem chegou hoje, pensa, nós temos uma usina no estado do Tocantins (Bolivar Alves Mendanha. Entrevista citada, 2011).

É importante destacar a expressão usada pelo entrevistado: “enxergar as coisas de outra forma", demonstrando que a consciência jurídica produz uma consciência do todo, das causas e efeitos, ou seja, não se trata apenas de uma usina, mas de uma complexidade que envolve o país e o planeta como um todo. Essa ideia de abrir os olhos é reforçada no depoimento de Gaspar Barbosa:

Era muito diferente, por exemplo, porque hoje acaso se fosse remanejar a gente, já sabia bem o direito da gente, num era igual nós saímos cego de um lugar para outro, removido de um lugar para outro. A pessoa viver sem saber viver, numa roça socado sem ter movimento, num lugar que num tinha nem televisão. Quando você chega no meio do povo que tem alguma sabedoria, você vai pegando qualquer coisa, se você quer ser ruim, tem ruim, se você quer meio bom, você vai pro meio do que é bom (Gaspar Barbosa Lima. Entrevista citada, 2011).

Para Gaspar Barbosa, a consciência jurídica representa aprender com os outros e saber escolher o que for melhor. Este depoimento se enquadra no que Salgado (2006) afirma sobre a formação da consciência baseada nas potencialidades do homem:

É o dever ser que dá nota da concepção do homem como ser que se projeta e se auto-engendra, que se forma, implica uma concepção axiogênica, pela qual o homem tem de postular-se como livre no processo da auto-educação que envolve tanto numa busca permanente do saber do mundo e sua transformação, do qual ela faz parte, como busca do saber de si como livre e sua formação como tal, num mundo por ele criado e que é o ambiente, o elemento da sua formação como livre (SALGADO, 2006, p. 19).

O processo de consciência jurídica não pode ser compreendido apenas à luz do conhecimento da norma e sua aplicabilidade no caso concreto. Neste caso, até as pessoas com formação em outras ciências poderiam ser consideradas sem consciência jurídica, afinal, também recorrem a um advogado para defender 
seus direitos. A consciência jurídica também não pode ser concebida apenas pela ótica do Direito Natural. Neste sentido, o Direito seria um conceito subjetivo, moldado pela cobertura sociocultural e pela consciência individual. O Direito, para ser exercido em sua plenitude, necessita um poder dominante que defina as normas de conduta e as faça cumprir, ou seja, para que haja segurança jurídica é necessário que exista um Estado de Direito.

O estudo de caso dos atingidos por barragem do reassentamento Córrego Prata demonstrou que a consciência jurídica é possível quando as pessoas têm acesso aos meios de justiça, e deles possam fazer uso. Mas para que isso possa ser possível é necessária a ação de sujeitos que possibilitem esta autoformação, porque depende da vontade livre do homem, que também é transformação, porque recebe a influência do outro. É o que se percebe no depoimento de Gaspar (Entrevista citada, 2011): "[...] era muito diferente, por exemplo, porque hoje acaso se fosse remanejar a gente já sabia bem o direito da gente, num era igual nós saímos cego de um lugar pra outro, removido de um lugar pra outro".

Reassentados são pessoas que tiveram sua história de vida bruscamente transformada pelo impacto causado com a construção da barragem. Muitas delas não sabiam o que fazer. Afinal, a maioria não era dona de terra, não tinha propriedade, porém, vivia do trabalho na fazenda, cuidando do pasto, zelando a sede, plantando uma pequena horta; ou então eram pessoas que possuíam uma casinha na beira do rio, onde pescavam e viviam do extrativismo. Quando receberam a notícia de que as terras onde viviam seriam tomadas pelo enchimento do lago, surgiu imediatamente o sentimento de medo e ansiedade: O que fazer? Para onde ir? Temos algum direito? Que direito?

Então, o que caracteriza a consciência jurídica? Pelos depoimentos de pessoas simples, muitas sem formação alguma, é possível compreender que a consciência jurídica é percebida quando o indivíduo toma conhecimento dos direitos garantidos pelas normas estabelecidas, e, como pessoa livre que é, julga a sua postura em face desses direitos, reivindicando-os ou deles dispondo livremente. Essa consciência não é estática, portanto, a tomada de consciência não significa um ponto de chegada ou de partida, mas uma continuidade, ou seja, um processo que tem um fim, não no sentido de final, mas de finalidade, propósito e apropriação. 


\section{CONSIDERAÇÕES FINAIS}

As entrevistas com os reassentados demonstraram que na fase préremanejamento eles desconheciam totalmente os seus direitos. Nessa condição, aceitavam passivamente as determinações da empresa, aguardando que ela ditasse quais eram os seus direitos.

Averiguou-se, também, que a maioria dos atingidos realocados para o reassentamento do Prata, eram empregados nas fazendas impactadas, e que a formação educacional máxima limitava-se ao ensino fundamental incompleto. Muitos confiavam nos patrões para saber se tinham ou não algum direito. Pelos relatos, algumas famílias receberam a visita do $\mathrm{MAB}$ antes de serem realocadas, e que chegaram a participar de reuniões com o objetivo de obter esclarecimentos e se mobilizar para a reivindicação dos seus direitos.

Foi a partir das reuniões promovidas pelo $\mathrm{MAB}$, da organização da Associação do Reassentamento Prata e da mediação do Ministério Público que muitos começaram a tomar consciência dos seus direitos e questionar se os tinham, e quais eram esses direitos. Ela surge quando o atingido vê o seu mundo ameaçado e, nesse momento, é forçado a tomar alguma atitude e lutar pelo seu direito.

A consciência jurídica é extraída da realidade vivida, subjetiva, do sentido que se dá às coisas e aos atos humanos. Esta realidade, ao ser regulada, torna-se normativa, jurídica e, portanto, validada. Essa consciência do direito é despertada quando o reassentado vê a sua liberdade ameaçada e toma consciência de que se deve lutar por ela.

Neste sentido, as respostas às questões levantadas na pesquisa ofereciam as informações necessárias para descrever esse processo. Os entrevistados rememoravam a vida antes do reassentamento, e como reagiram ao receber a notícia da desapropriação e do remanejamento para o reassentamento. Eles contavam quais foram as primeiras impressões ao chegarem ao reassentamento, $\mathrm{e}$ o que acharam desse novo lugar que estavam se apropriando. Também discorriam como foram tomando conhecimento dos seus direitos através dos contatos que tiveram com os representantes do MAB e do MP. Puderam expressar as suas experiências como sujeitos no processo, por meio da participação na Associação, quando debatiam os problemas do reassentamento e formulavam as suas propostas para a mesa de negociação com a INVESTCO. Discorreram sobre as suas expectativas, frustrações e diferenças vivenciadas no reassentamento.

Deduz-se que os reassentados passaram por diversas etapas para chegarem ao seu próprio entendimento do processo ao qual foram submetidos. Eles admitiam um estado de ignorância com relação aos seus direitos e consideravam-

Novos Cadernos NAEA • v. 16 n. 2 • p. 121-148 • dez. 2013 
se cegos. Por não conhecerem os seus direitos, em face da ameaça de perderem tudo o que conseguiram construir ao longo da vida, tinham a sensação de estar no escuro. Nesta condição, restava-lhes apenas confiar em alguém que lhes indicasse o que fazer e para onde ir.

A tomada de consciência não pode ser concebida como um ato súbito, ocorrido ao acaso. É um processo, uma formação, um exercício e uma conquista daqueles que ousam superar os seus próprios limites. Este processo não se desencadeia de forma isolada, pois é na vida social, na relação com a alteridade, que o sujeito descobre quem realmente é, na realidade em que se insere. Assim, o processo de consciência jurídica se desencadeia na sociedade civil, pois é nela que se encontra a gênese do direito. É nela que se travam os conflitos sociais e políticos, e as relações de poder, nas suas múltiplas formas. O direito emerge como ato de liberdade, que precisa coexistir com a liberdade de todos.

\section{REFERÊNCIAS}

BOBBIO, N. Estado, Governo e Sociedade.14. ed. São Paulo: Paz \& Terra, 2007.

CARVALHO, O. A. de. Águas sobre terra: lugar e territorialidade na implantação de grandes hidrelétricas. 2006. 186f. Dissertação (Mestrado em Geografia) Universidade Federal do Rio Grande do Sul, Porto Alegre, 2006.

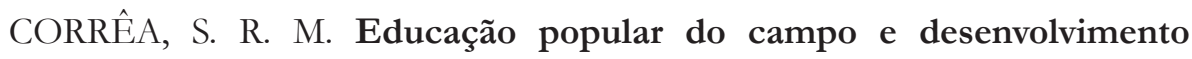
territorial rural na Amazônia: uma leitura a partir da pedagogia do Movimento dos Atingidos por Barragem. 2007. 353f. Dissertação (Mestrado em Educação) Centro de Educação, Universidade Federal da Paraíba, João Pessoa, 2007.

FERREIRA, M. A. Consciência moral e consciência jurídica. Belo Horizonte: Mandamentos, 2002.

FOSCHIERA, A. A. Da barranca do rio para a periferia dos centros urbanos: a trajetória do movimento dos atingidos por barragens face às políticas do setor elétrico no Brasil. 2009. 344f. Tese (Doutorado em Geografia) - Universidade Estadual Paulista "Júlio de Mesquita Filho", Presidente Prudente, 2009.

FOUCAULT, M. Microfísica do Poder. 11. ed. Rio de Janeiro: Graal, 1997.

FRANÇA, F. M.; SOUZA, E. B. C. de. Crise, práxis e autonomia: espaços de resistência e esperanças. Espaço de diálogo e práticas. Os impactos sócio-espaciais com a construção de hidrelétricas - um estudo de caso da usina hidrelétrica de Salto Caxias-PR. In: ENCONTRO NACIONAL DOS GEÓGRAFOS, 16. 2010. Porto Alegre. Anais... Porto Alegre, 2010. 
FURLIN, N. A noção de sujeito em Touraine e Foucault: contribuições epistemológicas para o pensamento social. In: CONGRESSO BRASILEIRO DE SOCIOLOGIA, 15. 2011. Critiba. Anais... Curitiba: UFPR, 2011.

KARPINSKI, C. Sobre as águas a memória: relações de poder e subjetividades durante a implantação da Usina Hidrelétrica Salto Caxias (Paraná, 1989-2001). 2007. 140f. Dissertação (Mestrado em História) - Universidade Federal de Santa Catarina, Florianópolis, 2007.

MELO, O. F. de. Temas atuais de política do direito. Porto Alegre: Sergio Antônio Fabris, 1998. Disponível em: www.advocaciapasold.com.br/ publicacoes/aconscienciajuridica.doc. Acesso em: 20 set. 2009.

MÜLLER, A. C. Hidrelétricas, meio ambiente e desenvolvimento. São Paulo: Makron Books, 1995.

NADER, P. Introdução ao estudo do direito. Rio de Janeiro: Forense, 2011.

NEVES, R. de A. Ensino Jurídico: avaliando a aprendizagem a partir de uma experiência de associação teoria/prática. 2005. Dissertação (Mestrado em Educação) - Universidade Federal de Pelotas, Pelotas, 2005.

PAIVA, V. (Org.). Igreja e a Questão Agraria. São Paulo: Loyola, 1985.

PARENTE, T. G.; MAGALHÃES, H. G. D. (Orgs.). Linguagens plurais: cultura e meio ambiente. Bauru: EDUSC, 2008.

PLANO de Desenvolvimento do Projeto De Reassentamento Córrego Prata PDR. Palmas, 2002.

REIS, M. J. Espaços vividos, migração compulsória, identidade: os camponeses do Alto Uruguai e a Hidrelétrica de Itá. 1998. 274f. Tese (Doutorado em Ciências Sociais) - Instituto de Filosofia e Ciências Humanas, Universidade Estadual de Campinas, Campinas,1998.

SALGADO, J. C. A idéia de justiça no mundo contemporâneo. Belo Horizonte: Del Rey, 2006.

SANTANA, E. Conexões: movimento social, educação popular e cinema: A experiência do Movimento dos Atingidos por Barragens de Chapada dos Guimarães - MT com o Cinema Circulante. 2008. 163f. Dissertação (Mestrado em Educação) - Instituto de Educação, Universidade Federal de Mato Grosso, Cuiabá, 2008.

SILVA JÚNIOR, J. M. Reassentamentos rurais da Usina Hidrelétrica Luís 
Eduardo Magalhães - Tocantins: a efetividade do programa de remanejamento populacional quanto à sua sustentabilidade socioambiental. 2005. $142 \mathrm{f}$. Dissertação (Mestrado em Ciências do Meio Ambiente) - Universidade Federal do Tocantins, Palmas, 2005.

THEMAG. Engenharia e Gerenciamento Ltda. Usina Hidrelétrica Lajeado: Estudo de Impacto Ambiental; Projeto Básico Ambiental - PBA. Remanejamento da população rural. [s. 1.],1998. il.

TOASSA, G. Conceito de consciência em Vigotski. Psicologia USP, v. 17, n. 2, p. 59-83, 2006.

TOURAINE, A. A busca de si. Rio de Janeiro: Bertrand Brasil, 2004.

VAINER C. B.; ARAÚJO, F. G. B. Implantação de grandes hidrelétricas: estratégias do setor elétrico, estratégias das populações atingidas. Revista Travessia, n. 6, jan.-abr., 1990.

VIANA, R. de M. Grandes barragens, impactos e reparações: um estudo de caso sobre a barragem de Itá. 2003. 193f. Dissertação (Mestrado em Planejamento Urbano e Regional) - Universidade Federal do Rio de Janeiro, Rio de Janeiro, 2003.

YIN, R. K. Estudo de Caso: planejamento e métodos. Tradução de Daniel Grassi. 2. ed. Porto Alegre: Bookman, 2001.

ZITZKE, V. A. A rede sociotécnica da Usina Hidrelétrica do Lajeado (TO) e os reassentamentos rurais das famílias atingidas. 2007. Tese (Doutorado Interdisciplinar em Ciências Humanas) - Universidade Federal de Santa Catarina, Florianópolis: UFSC, 2007. 
